\title{
Percepções Maternas Acerca das Habilidades Sociocomunicativas de Bebês
}

Maternal Perceptions About Babies' Sociocommunicative Skills

Percepciones Maternas Acerca de Las Habilidades SocioComunicativas de Bebés

Fabíola de Sousa Braz Aquino \& Nádia Maria Ribeiro Salomão

Universidade Federal da Paraíba
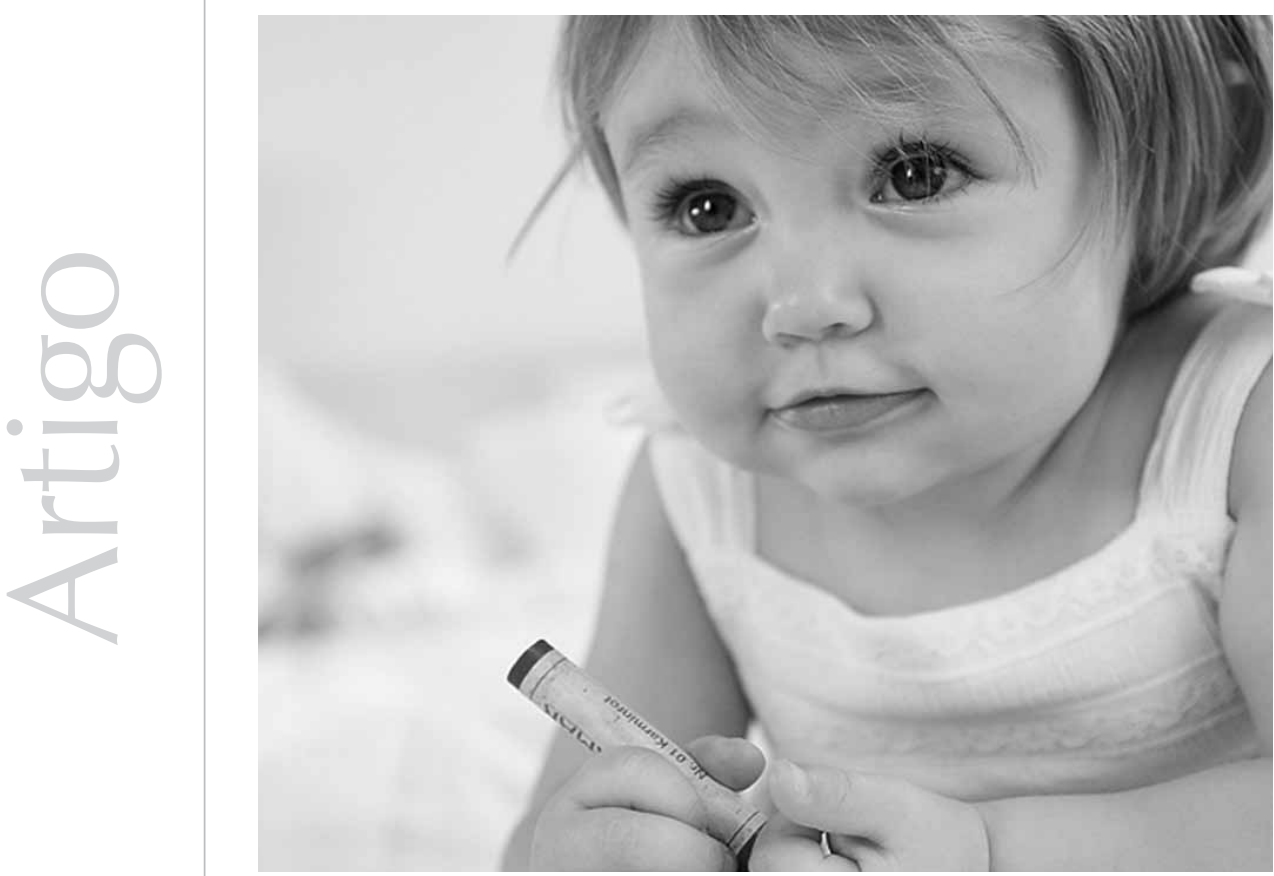
Resumo: O presente estudo investigou as percepções maternas acerca das habilidades sociocomunicativas de bebês no primeiro ano de vida. Partiu-se da ideia de que a percepção dos pais sobre a capacidade de comunicação intencional infantil pode influenciar a dinâmica das interações iniciais e as estratégias parentais para responder aos comportamentos dos bebês. Participaram da pesquisa 45 mães de bebês nas idades de seis, nove e doze meses. Para conhecer as percepções maternas acerca das habilidades de comunicação intencional dos bebês, foi utilizado o The Pragmatic Profile of Everyday Communication Skills in Children, uma entrevista semiestruturada que tem como centro os aspectos sociocomunicativos da linguagem. Os resultados indicaram variações nas percepções maternas em função da idade dos bebês, demonstradas por meio do relato de diferentes modalidades sociocomunicativas que, aos doze meses, englobaram o uso de gestos com vocalizações intencionais. Percebeu-se que parte das mães parecia desconhecer a presença de habilidades sociocomunicativas em seus bebês, o que pode repercutir nas interações estabelecidas. Considera-se que os dados deste estudo são importantes para a compreensão de pais e profissionais acerca da dimensão sociocomunicativa da linguagem, para a detecção precoce de alterações nas habilidades sociocognitivas de atenção conjunta e comunicação intencional bem como para o planejamento de intervenções que favoreçam o desenvolvimento infantil.

Palavras-chave: Comportamento materno. Comunicação mãe-criança. Relações mãe-criança. Vocalização do bebê.

Abstract: The purpose of this study was to analyse the maternal perceptions about babies' sociocommunicative skills in their first year of life. The study was based on the premise that the parents 'perception about the baby's intentional communication can influence the dynamics of the initial interactions and the parental strategies to respond to the babies' behaviours. This research involved the participation of 45 mothers of babies aged six, nine and twelve months old. In order to know the maternal perceptions about the babies' intentional communicative skills The Pragmatic Profile of Everyday Communication Skills in Children, a structured interview focused on sociocommunicative aspects of language, was used. The results indicated variation on the maternal perception related to the baby's age, indicated by the mothers' descriptions about different sociocommunicative abilities of their babies which, at twelve months, included the use of gestures with intentional vocalization. It showed, also, that some of the mothers seemed to ignore the presence of sociocommunicative abilities in their babies, what can influence the way they interact with their children. It is considered that the data of this study are important to the parents and professionals comprehension about the socioecommunicative dimension of language, to the detection of alterations on sociocommunicative abilities of joint attention and intentional communication, as well as for planning interventions to promote child development.

Keywords: Maternal behavior. Comunication mother child. Mother-child relations. Infant vocalization.

Resumen: El presente estudio investigó las percepciones maternas acerca de las habilidades sociocomunicativas de bebés en el primer año de vida. Se partió de la idea de que la percepción de los padres sobre la capacidad de comunicación intencional infantil puede influenciar la dinámica de las interacciones iniciales y las estrategias parentales para responder a los comportamientos de los bebés. Participaron en la pesquisa cuarenta y cinco madres de bebés en las edades de seis, nueve y doce meses. Para conocer las percepciones maternas acerca de las habilidades de comunicación intencional de los bebés fue utilizado el The Pragmatic Profile of Everyday Communication Skills in Children, una entrevista semi-estructurada, centrada en los aspectos socio-comunicativos del lenguaje. Los resultados indicaron variaciones en las percepciones maternas en función de la edad de los bebés, demostradas por medio del relato de diferentes modalidades socio-comunicativas que, a los doce meses, englobaron el uso de gestos con vocalizaciones intencionales. Se percibió que parte de las madres parecían desconocer la presencia de habilidades socio-comunicativas en sus bebés, lo que puede tener repercusiones en las interacciones establecidas. Se considera que los datos de ese estudio son importantes para la comprensión de padres y profesionales acerca de la dimensión socio-comunicativa del lenguaje, para la detección precoz de alteraciones en las habilidades socio-cognitivas de atención conjunta y comunicación intencional así como para la planificación de intervenciones que favorezcan el desarrollo infantil.

Palabras clave: Conducta materna. Comunicación madre-nino. Relaciones madres-ninos. Vocalicion infantil. 
Este estudo apresenta dados de uma pesquisa mais ampla que analisou as diferentes configurações de habilidades sociocomunicativas de bebês no primeiro ano de vida, em um contexto interativo. No conjunto de dados obtidos, considerou-se pertinente destacar as percepções maternas acerca das habilidades de comunicação de bebês em três períodos do primeiro ano de vida por entender que as percepções sobre essas habilidades podem mobilizar no adulto diferentes trocas interativas que vão se reconfigurando em cada período do desenvolvimento do bebê (Braz Aquino \& Salomão, 2008).

No estudo das interações mãe-bebê, um conjunto de pesquisas tem ressaltado o papel das concepções maternas acerca das habilidades sociocomunicativas e cognitivas de bebês no primeiro ano de vida (Dunn, 1999; Feldman \& Reznick, 1996; Feldman, 1999; Gomes, 2008; Seidl de Moura, Ribas, Piccinini, Bastos, Magalhães, Vieira, Salomão, Silva \& Silva, 2004, 2008a, 2008b; Parades \& Leerkes, 2008; Reznick \& Swartz, 2001). Esses estudos se baseiam no pressuposto de que a crença dos pais na capacidade de comunicação infantil pode influenciar a dinâmica das interações iniciais e as estratégias parentais para compreender e responder aos estados e metas dos bebês. Para esses mesmos pesquisadores, a percepção parental da habilidade comunicativa intencional dos seus bebês auxilia na promoção de um ambiente no qual a criança possa descobrir suas maneiras de adentrar de forma interativa no mundo devido aos estímulos proporcionados pelos pais nas interações.

Pesquisadores como Feldman e Reznick e Schwartz sustentam que a percepção dos pais acerca da intencionalidade comunicativa infantil influencia o tipo de input dirigido às crianças, as respostas dadas a elas nos momentos de interação estabelecidos, o prazer em interagir com a criança, o sentimento dos pais de eficácia ou rejeição em relação à criança e ainda a avaliação que os pais fazem de sua criança em comparação com outras. A importância da percepção parental acerca da intencionalidade comunicativa infantil foi assinalada em estudos (Reznick \& Schwartz, 2001) que verificaram ainda correlações entre a percepção parental acerca da intencionalidade comunicativa infantil e medidas de aquisição da linguagem relatadas pelos pais.

As percepções parentais acerca das habilidades de comunicação intencional nos bebês estão relacionadas a características de personalidade maternas que podem afetar a relação estabelecida com os bebês desde seus primeiros meses de vida, contribuindo para a explicação de aspectos dessa relação que poderiam prejudicar o desenvolvimento global infantil (Feldman \& Eidelman, 2004). Além das características maternas, devese considerar também as características individuais infantis, tais como o sexo e o temperamento das crianças, dado que estas podem influenciar a percepção parental sobre as habilidades infantis e a acuracidade dos relatos dos pais sobre as capacidades de seus filhos (Parade \& Leerkes, 2008).

Estudos (Feldman, 1999; Feldman \& Eidelman, 2004; Kreppner, 2000; Reznick, 1999) que abordam o papel das percepções parentais sobre a dinâmica das interações iniciais adultobebê ressaltam que investigar tais percepções possibilita ainda a detecção de prejuízos na comunicação e na linguagem, por meio de instrumentos que identificam e analisam os aspectos sociocomunicativos da linguagem, tais como os desenvolvidos por Feldman \& Reznick (1996), Wetherby e Prizant (1998) e Dewart e Summers (1995). Esses instrumentos são considerados importantes, dado que possibilitam identificar, por meio de relatos de adultos-cuidadores como os pais, tipos de interação adulto-criança e configurações do ambiente familiar que podem afetar o 
Camaioni, Aureli, Bellagamba

e Fogel (2003) observaram em seus estudos que, entre nove e doze meses de idade dos bebês, o início da comunicação intencional é marcada pela emergência de gestos dêiticos, tais como apontar, mostrar, oferecer e dar, e por solicitações ritualizadas: bater palmas, por exemplo. desenvolvimento sociocognitivo e emocional do bebê.

Investigar a compreensão das habilidades sociocomunicativas e cognitivas de bebês no primeiro ano da vida por parte dos pais é importante na medida em que promove informações sobre o desenvolvimento de processos mentais na infância que são cruciais para o subsequente desenvolvimento de aspectos sociocognitivos humanos, tais como a habilidade de atenção conjunta (Mundy, Block, Delgado, Van Heck, Pomares, \& Parlade, 2007). Já para Prior, Bavin, Cini, Reilly, Bretherton, Wake e Eadie (2008), o desenvolvimento da habilidade de comunicação na infância depende tanto de fatores intrínsecos quanto de influências extrínsecas na vida da criança. Para esses mesmos autores, o desenvolvimento da criança pode ser influenciado por fatores genéticos, pelo gênero da criança, pela saúde mental materna, pelo status socioeconômico dos pais, pelo tipo de ambiente e estrutura familiar da criança e pelos níveis de estimulação propiciados pela família.

Já para pesquisadores como Feldman, Greenbaum, Mayes e Erlich (1997) e Feldman e Eidelman (2004), é importante assinalar as relações entre as habilidades comunicativas pré-linguísticas infantis e a responsividade materna durante as interações iniciais mãe-bebê, esta última considerada um dos elementos essenciais para experiências favorecedoras do desenvolvimento global infantil. Nessa vertente de estudos, compartilha-se a ideia de que a origem, a forma e o desenvolvimento dos processos comunicativos se encontram na interação que a criança estabelece com a pessoa que dela cuida, especialmente a mãe, isso porque as primeiras habilidades sociocomunicativas ganham sentido quando são interpretadas e compartilhadas por ambos os parceiros na interação, tendo o adulto o papel de auxiliar a criança na co-construção de suas habilidades pré-linguísticas, atribuindo significado aos comportamentos e vocalizações infantis (Bruner, 1980; Hobson, 1989; Rivero, 2003; Tronick, 1989).

Deve-se lembrar que as habilidades sociocomunicativas intencionais infantis incluem o uso, por parte dos bebês, de gestos e vocalizações que frequentemente deflagram no adulto um conjunto de estilos comunicativos e verbais dirigidos ao infante que contribuem para o desenvolvimento de habilidades sociocognitivas e linguísticas infantis. Essas habilidades incluem principalmente o uso de gestos (sorriso, expressões faciais, posturas corporais) acompanhados muitas vezes por vocalizações que vão, ao longo do primeiro ano de vida, ganhar contornos comunicativos de natureza intencional (Bruner, 1999; Feldman, 2007; Franco, 2007; Holliday, 1979; Striano \& Rochat, 2000; Tomasello, 1995, 2003; Volterra, Caselli, Capirci, \& Pizzuto, 2004).

Camaioni, Aureli, Bellagamba e Fogel (2003) observaram em seus estudos que, entre nove e doze meses de idade dos bebês, o início da comunicação intencional é marcada pela emergência de gestos dêiticos, tais como apontar, mostrar, oferecer e dar, e por solicitações ritualizadas: bater palmas, por exemplo. Como ferramentas comunicativas, acrescenta-se nesse período o surgimento de sons semelhantes a palavras para comunicar uma intenção. Após esse período, entre doze e quinze meses, os bebês passam a fazer uso de um novo tipo de gesto chamado representacional ou simbólico, que denota um referente específico que se mantém independente do contexto, como, por exemplo, quando a criança acena para se despedir de alguém ou coloca o telefone no ouvido. Também Volterra, Caselli, Capirci e Pizzuto (2004) verificaram que, antes do primeiro ano de vida, as crianças começam a se comunicar intencionalmente, principalmente por meio de gestos, sendo 
estes, muitas vezes, acompanhados por vocalizações. Para essas autoras, há uma interação e uma continuidade entre os gestos e a fala, as primeiras formas linguísticas préverbais e uma subsequente linguagem formal, cuja ocorrência se dá em grande parte em um contexto de atenção conjunta.

Em relação a essa temática, foi encontrada por Messinger e Fogel (1998) uma estreita relação entre a idade e o aumento de diversos tipos de ações comunicativas, a idade e o aumento na proporção do tempo em que as crianças coordenavam sua atenção entre um objeto e o parceiro, e ainda, uma relação entre idade, aumento na vocalização de caráter comunicativo intencional e número de vocalizações que acompanham os gestos infantis. Hsu e Fogel (2001) destacam que comportamentos como o olhar e as expressões faciais são formas iniciais utilizadas pelos bebês para se comunicarem com os outros, e que a comunicação que se dá pela via das trocas não verbais e afetivas é geradora de futuras ações que serão coordenadas mutuamente e reguladas por ambos os parceiros da díade.

Autoras como Dunn (1999) afirmam que as atribuições de intencionalidade e a responsividade do adulto aos comportamentos dos bebês permitem que os mesmos desenvolvam uma compreensão do significado de suas ações para com os outros. A partir desse prisma, as expressões das emoções dos bebês são pistas importantes para poder atribuir a intenção dos pais aos comportamentos infantis. Em outras palavras, nas primeiras trocas adulto-bebê, a dimensão socioemocional seria imprescindível para integrar o sistema comunicativo do bebê às demais dimensões do desenvolvimento infantil (Adamson \& Bakeman, 1985; Bloom, 1993; Karousou, 2003; Rivero, 2003).

Os estudos acima referidos acentuam a relevância das habilidades sociocomunicativas para a aquisição da linguagem e da cognição social infantil, com destaque para o papel das primeiras interações adulto-bebê e das percepções parentais acerca das habilidades sociocomunicativas infantis, sob o enfoque sociopragmático. Em relação ao presente estudo, sua contribuição recai na apresentação de dados empíricos especificamente relacionados às percepções maternas acerca das habilidades sociocomunicativas e pragmáticas de bebês no primeiro ano de vida, dados relevantes para melhor compreensão dessa temática no contexto brasileiro. Considerando a repercussão dessas percepções nas interações iniciais e no desenvolvimento global infantil, o objetivo da presente pesquisa foi conhecer as percepções maternas acerca das habilidades sociocomunicativas dos bebês em três momentos do primeiro ano de vida.

Método: o delineamento de pesquisa utilizado foi o transversal, que permite comparar comportamentos diferentes de sujeitos em diferentes idades, possibilitando a aquisição de informações em um grupo maior (Lavelli, Pantoja, Hsu, Messinger, \& Fogel, 2004). A pesquisa foi submetida ao Comitê de Ética do Centro de Ciências da Saúde da Universidade Federal da Paraíba, obtendo um parecer favorável e, portanto, a autorização, pelos referidos avaliadores, para a realização do estudo.

Participantes: participaram deste estudo 45 mães de bebês nas idades de seis, nove e doze meses, igualmente distribuídas por grupo de idade. O número de mães por grupo foi assim delimitado em função da dificuldade de obter participantes que atendessem aos critérios de inclusão da pesquisa e que concordassem em participar do estudo. Como critérios de inclusão, buscou-se obter um grupo equiparado no que se refere às variáveis nível de instrução, nível socioeconômico, estado civil e idade materna acima de 20 anos. Essas mães pertenciam a famílias de 
nível socioeconômico médio caracterizada principalmente pelo nível de instrução, que variava de médio completo ao superior incompleto, pela renda familiar e pelo local de residência. Dessa forma, as mães dos bebês eram casadas, moravam em suas próprias residências e tinham idade média de 27,7 anos. Segundo referido pelas mães, os bebês não apresentavam problemas de saúde e haviam nascido a termo (idade gestacional maior que 38 semanas).

Instrumento: para conhecer as percepções maternas acerca das habilidades sociocomunicativas dos bebês, utilizou-se uma entrevista estruturada e caneta. A entrevista realizada com as mães foi The Pragmatics Profile of Everyday Communication Skills in Children (edição revisada de Dewart \& Summers, 1995), instrumento que passou por um processo de adaptação semântica realizada por Braz Aquino e Salomão (2008). O The Pragmatics Profile of Everyday Communication Skills in Children consiste em uma entrevista estruturada centrada nos aspectos sociopragmáticos da linguagem.

Essa entrevista enfatiza uma abordagem qualitativo-descritiva das informações e relatos sobre como a criança se comunica em sua vida diária. Dessa forma, essa entrevista deve ser abordada diferentemente dos métodos tipicamente quantitativos, pois sua validade não é estabelecida por correlações com escores de outras escalas, mas por meio da literatura da área sobre a pragmática. Em relação a isso, as informações de cada entrevista são baseadas nas percepções dos entrevistados e na obtenção de recursos complementares, tais como entrevistas com outro parente e professores da criança. Além disso, os recursos para obter informações acerca das habilidades sociocomunicativas sugeridas por Dewart \& Summers (1995) incluem observações estruturadas ou em ambiente natural e análise de discursos, processo de triangulação vital para validar pesquisas qualitativas. Optou-se pela utilização dessa entrevista por se considerála um instrumento que investiga os aspectos comunicativos e intencionais da linguagem.

O The Paragmatic Profile of Everyday Communication Skills in Children consiste em uma entrevista centrada em quatro aspectos do desenvolvimento da pragmática: o desenvolvimento da função comunicativa (a maneira como a criança se torna apta a expressar suas intenções, tais como solicitações ou perguntas, saudações ou cumprimentos, e dar informações através de uma variedade de comportamentos comunicativos, como gestos, vocalizações e linguagem verbal); as respostas da criança à comunicação (a maneira como a criança reage e compreende a comunicação de outras pessoas); a participação em interações sociais e na conversação (a criança é percebida como um participante na interação, e, nas interações que incluem iniciação no diálogo por parte desta, trocas conversacionais e reparos no diálogo), e as variaçóes no contexto (tais como o tempo, o local e as pessoas envolvidas na interação). É importante mencionar que a análise dos dados se concentrou nas respostas mais especificamente relacionadas à dimensão sociopragmática da linguagem, isso porque o referido instrumento aborda aspectos mais gerais do desenvolvimento infantil, que incluem a essa dimensão.

Essa entrevista utiliza-se de uma linguagem facilmente compreensível e sem palavras de cunho mais formal ou estilizado. Na entrevista, são também evitadas questões do tipo sim/ não e informações retrospectivas, sendo o seu foco os comportamentos da criança em seu momento atual (ex. O que você faz quando quer chamar a atenção de seu bebê?; Se você aponta para alguma coisa que você deseja que seu bebê olhe, o que ele/ela faz?). A base da entrevista são questões abertas que permitem aos entrevistandos dar suas próprias respostas e descrever os comportamentos comunicativos 
da criança com as próprias palavras, embora sejam sugeridos em cada questão exemplos para auxiliar os respondentes a focarem os comportamentos que a criança possa exibir em cada situação apresentada (Dewart \& Summers, 1995).

Procedimentos para coleta: a entrevista com as mães foi realizada individualmente, evitando-se o mínimo possível de interferência no momento de sua realização. As mães foram contatadas por meio de pessoas que conheciam mulheres que tinham bebês nas idades de seis, nove e doze meses, e nos critérios de inclusão tais como mães dos bebês casadas, que morassem em seus próprios domicílios, que tivessem idade a partir de 20 anos e possuíssem nível de instrução a partir do ensino médio completo. Durante as aplicações, apenas estavam presentes a mãe e a pesquisadora. Foi perguntado às mães se algum item do questionário não havia sido compreendido, não sendo relatadas pelas respondentes dificuldades de compreensão das questões do instrumento. A única instrução dada à mãe foi que "ela respondesse a cada questão pensando em sua criança naquele momento de seu desenvolvimento", já que "não há, para a entrevista, respostas 'certas ou erradas'.

Análise dos dados: após realizadas as entrevistas, as respostas das mães à entrevista foram categorizadas tendo em vista as quatro sessões do referido instrumento: funções comunicativas, resposta à comunicação, interação e diálogo e variação contextual. Depois de categorizadas, as respostas das mães foram organizadas em termos de frequência e discutidas a partir de dados da literatura referentes aos aspectos sociocomunicativos da linguagem e suas imbricações com as interações iniciais mãebebê.

\section{Resultados e discussão}

\section{a) Funções comunicativas}

A primeira sessão da entrevista visa a levantar informações acerca das funções comunicativas presentes nos bebês. Em relação às percepções maternas acerca das habilidades dos bebês para chamar a atenção da mãe, verificou-se, conforme relato materno, que a maioria do grupo das 15 mães de bebês na idade de seis meses mencionou, como principais recursos comunicativos, o choro (48\%), o ato de apontar (43\%) e a vocalização (30,4\%). Como o ato de apontar em bebês tem sido relatado pela literatura (Carpenter, Nagell, \& Tomasello, 1998; Tomasello, Carpenter, \& Liszkowski, 2007; Volterra et al., 2004; Woodward, 2007) como um comportamento observado aos nove e, principalmente, aos doze meses, a menção por parte das mães do ato de apontar nos seus bebês aos seis meses pode estar relacionada à percepção que a mãe tem do que vem a ser o gesto de apontar.

Esse ato é considerado por alguns pesquisadores (Leavens \& Hopkins, 1999; Franco, 2007; Woodward, 2007) como um dos principais tipos de gestos sociais que emergem em torno do final do primeiro ano de vida, frequentemente coordenado com outros comportamentos comunicativos tais como os gestos e vocalizações intencionais. No relato das mães, foi verificada a menção à vocalização, algo que também necessita ser melhor investigado, dado que as mães podem estar equiparando os balbucios próprios dos bebês dessa idade com vocalizações típicas de bebês que estão no final do primeiro ano de vida. Aqui também seria prudente verificar se as mães estariam atribuindo a habilidade de vocalização do bebê a uma possibilidade de comunicação com ele.

No que tange aos dados obtidos acerca das percepções maternas das habilidades 
comunicativas dos bebês aos nove meses, os resultados encontrados demonstram que o choro $(29,2 \%)$, o gesto de puxar a mãe $(29,2 \%)$ e de vocalizar (19,5\%) foram os principais comportamentos dos bebês utilizados para obter a atenção das mães, conforme relato materno. Como se pode observar, esses relatos acerca dos tipos de comportamentos dos bebês sofrem variações quando comparados em cada idade. Pesquisadores (Volterra et al., 2004), verificaram que, entre as idades de nove e treze meses, os bebês já utilizam gestos como vocalizar e puxar a mãe para obter a atenção desta, comportamentos mais frequentemente citados por mães desse grupo.

As mães de bebês com doze meses mencionaram que os mesmos utilizavam, para chamar a atenção das mães, o choro $(27,7 \%)$, a vocalização (25\%) o gesto de puxar a mãe para perto de si $(22,2 \%)$ e a vocalização "mamã" (22,2\%). Deve-se destacar que parte das mães desse grupo citou o uso, pelos bebês, de pequenas palavras, o que modifica significativamente o tipo de interação estabelecida, já que agora os bebês utilizam, além de gestos, palavras que auxiliam as mães na compreensão da intenção comunicativa do bebê. As mães desse grupo também mencionaram a vocalização encadeada com o choro e o comportamento de puxar a mãe para perto de si, este último considerado um gesto protoimperativo (Volterra et al., 2004). No que tange às habilidades comunicativas utilizadas pelos bebês para demonstrar algo de seu interesse, as mães dos bebês de seis meses mencionaram que eles apontavam $(43,5 \%)$ e apontavam e olhavam para a mãe $(21,7 \%)$. Já as mães de bebês de nove meses mencionaram com mais frequência o uso do gesto de apontar para o objeto e olhar para a mãe (27\%), apontar (23,3\%) e apontar e vocalizar algo (21\%). Nas mães de bebês de doze meses, foram mencionados comportamentos comunicativos dos bebês como apontar para o objeto e vocalizar
$(42,8 \%)$, apontar para o objeto $(25 \%)$ e apontar para o objeto e tornar a olhar para a mãe $(21,4 \%)$. O gesto de olhar para o adulto coordenado com o ato de apontar tem sido relatado (Franco, 2007; Tomasello et al., 2007) como um tipo de comportamento comunicativo intencional.

No que concerne à percepção materna acerca das habilidades dos bebês para reconhecer algo e nomeá-lo ou comunicar à mãe que identificou um objeto, os relatos maternos relativos aos bebês de seis meses incluíram vocalização (30,4\%), o gesto de apontar para o objeto $(21,7 \%)$ e olhar e sorrir para o objeto (13\%). Já o grupo de mães de bebês com nove meses mencionou a vocalização $(26,4 \%)$, fazer gesto (16,8\%) e fazer som relacionado $(4,8 \%)$, como "miau" para se referir a gato. No grupo de mães de bebês com doze meses, as principais habilidades citadas foram vocalizar $(34,3 \%)$, fazer som relacionado (25\%) e fazer gestos (21,8\%). Percebe-se que, nesse último grupo, aumenta a menção ao uso da vocalização fazendo som relacionado a um objeto, recurso comunicativo menos mencionado pelas mães de bebês com seis meses.

A menção das mães de bebês de nove e doze meses à habilidade de fazer um som relacionado a um objeto pode demonstrar um novo tipo de estratégia comunicativa dos bebês que instaura processos interativos mediados por pequenas palavras, antes não observados, conforme relato das mães. Pesquisadores como Bruner (1980) ressaltam a importância dos momentos nos quais a mãe promove a referência entre um ato, um objeto e o seu rótulo linguístico; esses episódios estruturam o ambiente, auxiliando o bebê a delimitar para qual aspecto do contexto sua atenção deve ser dirigida, contribuindo para uma compreensão crescente do mesmo acerca do mundo circundante e do significado e do uso das palavras no contexto. 


\section{b) Resposta à comunicação}

No que tange às percepções maternas acerca dos comportamentos das mães para obter a atenção do bebê, as mães dos bebês de seis meses mencionaram como estratégias comunicativas dizer o nome do bebê (40\%), tocar nele $(26,7 \%)$ e movimentar-se próximo dele $(16,7 \%)$. Já as mães de bebês de nove meses citaram como principais estratégias para obter a atenção do bebê dizer o nome do bebê (39\%), tocar nele (18,2\%) e movimentar-se próximo à face de seu bebê (10,4\%). Já aos doze meses, os recursos comunicativos parecem ter se modificado, e as mães mencionaram como principal forma de obter a atenção dos bebês dizer o nome do bebê $(70 \%)$ e tocar nele (25\%), o que pode indicar que as mães concebem que seus bebês já reconhecem e distinguem seu próprio nome dos demais rótulos linguísticos de seus contextos.

Quando indagadas acerca de como o bebê responde às solicitações e a fala materna durante as interações, as mães de bebês de seis meses relataram que eles mostravam pouco interesse (33,3\%), olhavam interessados e faziam contato visual (33,3\%) e movimentavam seu corpo e face (25\%). As mães de bebês de nove meses relataram que estes respondiam às mães através do contato visual $(26,1 \%)$, mostravam pouco interesse $(23,2 \%)$ e movimentavam seu corpo e face (20,3\%). Já as mães de bebês de doze meses disseram que eles respondiam às tentativas de interação da mãe, olhando interessados e fazendo contatos visuais (38,4\%), juntando-se à conversa usando sons e palavras (26,9\%) e, ainda, mostravam pouco interesse (26,9\%). Pesquisadores como Hsu e Fogel (2001) destacam que comportamentos como o olhar e as expressões faciais são formas iniciais utilizadas pelos bebês para se comunicarem com os outros, e que a comunicação que se dá pela via das trocas não verbais e afetivas é geradora de futuras ações que serão coordenadas mutuamente e reguladas por ambos os parceiros da díade.

É importante refletir sobre o dado de que parte das mães mencionou que, durante as interações, os bebês mostravam pouco interesse; essa percepção do comportamento do bebê pode influenciar nas atitudes e relações que ela desenvolve com ele. A menção a esse comportamento pode ser derivada da forma como a mãe interpretou a atenção breve e curta dos bebês, principalmente aos seis meses (Franco, 2007; Woodward, 2007). Como no período em torno dos seis meses o bebê começa a incorporar à sua vida social os objetos para além da relação diádica (adulto-bebê ou bebê-objeto), há um esforço constante do bebê em adaptar-se às múltiplas experiências e às situações de mediação propostas constantemente pelas mães no intuito de envolver o bebê na interação. Além disso, o fato de o bebê não estar sempre respondendo aos chamados da mãe não significa que ele não esteja, em algum nível, atento aos aspectos do ambiente (Rivero, 2003; Reddy, 2007).

Considera-se que os comportamentos relatados pelas mães em relação aos tipos de respostas dos bebês às solicitações maternas estariam relacionados à natureza da atenção e à qualidade de envolvimento mútuo dos bebês, principalmente aos seis meses, marcados pelo olhar breve e fortuito. As mães pesquisadas provavelmente não compreendem que nessa idade o olhar do bebê parece flutuar entre o mundo social (pessoas) e o mundo físico (objetos), e que a habilidade de focar a atenção por um certo período se encontra em processo de amadurecimento (Tomaselo, 2003). Já autores como Papaeliou \& Trevarthen (2006) consideram que a qualidade de envolvimento do bebê em um contexto específico é facilitado por modalidades expressivas, que incluem gestos, expressões faciais, orientações 
posturais e vocalizações. Para eles, os bebês são particular e inicialmente mais sensíveis à regulação emocional propiciada pelas trocas interpessoais mais do que por qualquer exploração do ambiente físico. Também Adamson \& Bakeman (1985) assinalaram que a regulação afetiva e suas manifestações durante as interações mãe-bebê possuem um papel crítico na compreensão do desenvolvimento da comunicação.

Quando perguntado às mães acerca da habilidade do bebê para seguir o apontar da mãe para objetos do ambiente, as mães dos bebês de seis meses mencionavam que eles olhavam para a mãe e não para onde ela estava apontando (40,7\%), não davam resposta $(25,9 \%)$ e olhavam para onde a mãe apontava, se o objeto estivesse próximo $(22,2 \%)$. Esses resultados são congruentes com dados de pesquisas que relatam que a habilidade do bebê para seguir o gesto de apontar do adulto ocorre por volta dos dez meses de idade (Carpenter, Nagell, \& Tomasello, 1998).

Já as mães de bebês de nove meses observaram que eles olhavam para a mãe, e não para onde ela estava apontando (19,8\%) e olhavam para o objeto apontado, mesmo que estivesse distante (11\%), enquanto as mães de bebês com doze meses mencionaram que estes olhavam, se $O$ objeto estivesse próximo ((30,4\%), olhavam, mesmo se o objeto estivesse distante (26\%), e olhavam para a mãe, e não para onde ela estava apontando (21,7\%). Os dados obtidos dos relatos das mães de bebês de nove e doze meses indicam novas aquisições na habilidade de seguir o gesto de apontar, um dos principais indicadores da capacidade dos bebês de estabelecer episódios de atenção conjunta e de compreender as intenções comunicativas do outro (Striano \& Rochat, 2000; Tomasello, 2003).

No que concerne às percepções maternas acerca das habilidades dos bebês de compreender as intenções comunicativas do adulto, as mães dos bebês de seis meses responderam que eles não mostravam reação $(57,8 \%)$ ou apontavam ou faziam gestos $(15,7)$. Já as mães de bebês de nove meses mencionaram que os bebês não mostravam reação $(25,3 \%)$, sorriam (23\%) ou apontavam ou faziam gestos $(16,1 \%)$. As mães de bebês de doze meses mencionaram que seus filhos apontavam ou faziam gestos (40,9\%), mostravam algo para a mãe $(27,2 \%)$, não mostravam reação $(13,6 \%)$, falavam utilizando uma só palavra, e compreendiam, mas só respondiam quando queriam (4,5\%). Observou-se, nesses relatos, uma variação no relato das mães desse tipo de habilidade quando comparada às idades dos bebês, as quais estão atreladas a novas aquisições derivadas do próprio processo de desenvolvimento dos bebês, principalmente quando se observam os relatos das mães de bebês de seis e doze meses.

A menção das mães, nas três idades, da resposta não mostra reação pode sugerir que elas não atribuem aos seus bebês a habilidade de comunicação intencional, embora se perceba que, no grupo de mães de bebês com doze meses, essa resposta tenha sido mencionada com menor frequência. Pesquisadores como Gros-Louis, West, Goldstein e King (2006) verificaram em seu estudo que, durante as interações com os filhos, as mães parecem perceber que o bebê está realmente falando ou se comunicando intencionalmente quando produzem sons silábicos, provavelmente porque as emissões do bebê no primeiro ano de vida podem ter para o adulto uma qualidade infrafonológica. Segundo relatam, os adultos parecem distinguir as vocalizações pré-linguísticas por suas pistas caracteristicamente mais salientes, como os diferentes tipos de choro e o conteúdo de vocalizações não vegetativas. Assim, é possível que as mães pesquisadas ainda não concebam o bebê como um ser comunicativo intencional por, provavelmente, 
relacionarem a comunicação à linguagem oral e à produção de sílabas canônicas.

\section{Interação e diálogo}

Em relação aos tipos de participação dos bebês nas interações com as mães, foi relatado pelas mães dos bebês de seis meses que eles olhavam interessados um para o outro $(34,6 \%)$, sorriam e davam gargalhadas $(34,6 \%)$ e vocalizavam ou balbuciavam $(11,5 \%)$. Essas duas primeiras categorias de resposta seriam fortes indicadores sociais, já que o olhar e o sorriso dirigidos ao outro são comportamentos basilares para o estabelecimento da comunicação e de um engajamento conjunto (Hains \& Muir, 1998; Hobson, 2007; Trevarthen, 2004).

No que se refere às mães de bebês de nove meses, foi mencionado que eles sorriam e davam gargalhadas $(20,7 \%)$, olhavam interessados um para o outro $(18,8 \%)$ e vocalizavam e balbuciavam (15\%). As mães de bebês de doze meses relataram que eles sorriam e davam gargalhadas, (30,2\%), apontavam, mostravam e faziam menção de tocar e pegar no outro $(23,2 \%)$ e vocalizavam e balbuciavam $(23,2 \%)$. Os relatos das mães sobre os tipos de participação dos bebês nas interações nessa idade são congruentes com dados da literatura que também destacam o sorriso e o estabelecimento do contato visual como comportamentos básicos e fundamentais para o favorecimento da comunicação social (Cleveland, Kobiella, \& Striano, 2006; Papaeliou \& Trevarthen, 2006). Nesses contextos, a responsividade materna constitui elemento fundamental para que o bebê, desde os primeiros meses de vida, possa internalizar formas de comunicação e artefatos socioculturais tipicamente humanos (Vygotsky, 1996).

Quanto às formas utilizadas pelos bebês para iniciar uma interação com as mães, foram mencionados o uso, por parte dos bebês de seis meses, de gestos (29,2\%), o gesto de se aproximar e olhar para o rosto da mãe (25\%) e de dar ou mostrar algo para a mãe $(20,8 \%)$. Nesse grupo de respostas, destaca-se a menção das mães de gestos comunicativos intencionais como dar e mostrar algo à mãe e aproximar-se e olhar para o rosto da mãe, comportamentos também relatados pela literatura como observados nos bebês geralmente no final do primeiro ano de vida (Striano \& Bertin, 2005; Striano \& Vaish, 2006). Seria interessante investigar o que a mãe designa dar ou mostrar em um bebê aos seis meses, e ainda o que ela concebe como aproximar-se e olhar para o rosto da mãe. Questiona-se inclusive se o bebê nessa idade teria habilidades psicomotoras para comportamentos dessa natureza.

As mães de bebês na idade de nove meses mencionaram que os filhos faziam pequenos sons $(36,3 \%)$, buscavam os olhos da mãe $(29,7 \%)$, aproximavam-se dela e olhavam para seu rosto (26, 4\%). Cleveland et al. (2006) lembram que o contato visual, representado aqui pela resposta buscar os olhos das mães, é um importante elemento que auxilia o bebê a reconhecer quando a interação social está começando e quando está terminando, sendo ainda um importante indicador comunicativo a ser identificado nos bebês desde os seus primeiros meses de vida. Aos doze meses, foi relatado pelas mães que os bebês davam ou mostravam algo à mãe $(41,3 \%)$, faziam pequenos gestos (31\%), aproximavam-se da mãe e olhavam para o seu rosto.

Por outro lado, no que se refere às percepções acerca dos sinais que os bebês dão de término da interação, as mães relataram, como comportamentos dos bebês aos seis meses, olhar para longe (56\%), sair de perto da mãe $(31,3 \%)$ e parar de olhar para a mãe $(6,3)$. O comportamento de olhar para longe tem sido relatado como um importante indicador nos bebês de respostas a uma face neutra 
Também Yale, Messinger, Delgado e CoboLewis (2003) relataram que os bebês, no primeiro ano de vida, usam vocalizações, expressões faciais e a direção do olhar quando interagem com outros para comunicar intenções específicas que mudam com a idade. ou estática ou um sinal de que o bebê poderia estar interpretando uma intenção comunicativa, da mãe, de término de um episódio interativo (Striano \& Bertin, 2005; Cleveland et al., 2006). Como o contato visual é parte determinante da comunicação social (Hains \& Muir, 1998), o comportamento de olhar para longe sinalizaria para as mães uma espécie de desinteresse ou tédio do bebê em relação a algum evento.

Sobre essa mesma questão, as mães de bebês de nove meses citaram com menor frequência o comportamento de sair de perto da mãe (20,9\%) e de olhar para longe $(9,5 \%)$, enquanto as mães de bebês de doze meses citaram o ato de sair de perto da mãe $(68,4 \%)$ e de olhar para longe $(55,5 \%)$ com uma frequência mais elevada que as mães de bebês de seis meses. Destaca-se que o comportamento de sair de perto da mãe, mencionado pelas mães de bebês com idades de nove e doze meses, seria também derivado das novas aquisições motoras advindas nos bebês dessas idades.

Também Yale, Messinger, Delgado e CoboLewis (2003) relataram que os bebês, no primeiro ano de vida, usam vocalizações, expressões faciais e a direção do olhar quando interagem com outros para comunicar intenções específicas que mudam com a idade. Conforme esses autores, o rápido desenvolvimento das habilidades das crianças nos primeiros meses de vida ocorre para combinar ações de diferentes modalidades de comportamentos em padrões específicos, como, por exemplo, vocalizações que podem se iniciar e terminar com um sorriso ou um olhar para a face da mãe.

No que se refere à sessão da entrevista relativa à variação do contexto, os relatos maternos demonstraram poucas variações. Em geral, a família (pais, avós e tios) foi considerada o grupo com quem o bebê manifesta mais gostar de interagir. Também foi relatado, por parte das mães dos bebês de doze meses, que eles "ainda não demonstram reação" (duas mães), sendo que uma das mães não respondeu a essa questão. Em relação às situações nas quais o bebê é mais comunicativo, o ambiente familiar, como a casa do bebê e dos avós, foi a resposta mais citada pelas mães dos bebês nas duas idades pesquisadas. No que se refere ao momento do dia em que o bebê demonstra ser mais comunicativo, as respostas mais frequentes foram os momentos em que toma banho, quando brinca e ao acordar.

Ainda nessa parte da entrevista, buscou-se conhecer de que forma os bebês reagem à situação de leitura de livro. Os relatos maternos variaram em torno de respostas tais como: olha os livros com auxílio dos adultos e ouve histórias; ouve histórias, embora ainda não entenda (nove meses), e presta atenção às figuras de crianças por mais tempo. Considera-se importante mencionar que duas mães de bebês com nove meses deram como resposta "ele ainda não faz", e outras duas não responderam ao item. Foram mencionados ainda, de forma isolada, que "o bebê adora olhar e folhear livros" e "olha as gravuras". Em relação aos comportamentos dos bebês com outras crianças, foi relatado pela maioria das mães, em ambas as idades, que os bebês "brincavam com outros", sendo citado por apenas uma das mães, em ambas as idades, que o bebê brincava sozinho. Também foi relatada a necessidade de participação e orientação de adultos nos momentos em que os bebês brincavam com outras crianças. Nos estudos sobre concepções maternas acerca do desenvolvimento infantil realizados com participantes brasileiras, destacamse os de Seidl de Moura et al., (2004, 2008 a, b) e Ribas Jr., Seidl de Moura e Bornstein (2007). As análises desses estudos referentes às cognições parentais sobre as competências gerais de bebês permitiram identificar que as mães participantes desses estudos percebiam seus filhos como ativos 
nas trocas interacionais, resultado também encontrado na presente pesquisa ao se analisarem as percepções maternas acerca das habilidades sociocomunicativas infantis. Também nos estudos dos referidos autores foram encontrados efeitos significativos relacionados às variáveis cognições parentais e escolaridade materna. Já no presente estudo foram observadas diferenças nas percepções maternas em função das novas habilidades apresentadas pelos bebês em cada idade estudada.

Também no presente estudo pôde-se perceber que a maioria das mães entrevistadas relatou habilidades comunicativas de seus bebês, embora parte dos relatos indique que a habilidade de comunicação através da fala ainda seja, para as mães, o principal elemento que denotaria a capacidade dos bebês de se comunicar. A maioria das mães de bebês de nove e doze meses relatou um conjunto de atos comunicativos já considerados de natureza intencional nos bebês dessa idade. Contudo, seria interessante verificar se a menção a esses comportamentos estaria atrelada ao conhecimento, por parte das mães, de que tais atos são comunicativos e de que carregam o propósito do bebê de obter atenção do adulto para realizar uma atividade.

É importante pontuar que o The Pragmatic Profile of Everyday Communication Skills in Children pode ser utilizado como uma ferramenta para pesquisadores que visam a um maior aprofundamento de dados referentes à comunicação e às habilidades de bebês e crianças em contextos diários, educacionais e sociais de maneira geral. No contexto familiar e escolar, o conhecimento de tais habilidades por parte dos adultos pode promover trocas sociais mais favorecedoras do desenvolvimento e da aprendizagem infantis. A análise dos relatos de adultos acerca do conjunto de habilidades expressas pelo bebê já no primeiro ano de vida possibilita aos profissionais de saúde a detecção de possíveis alterações em habilidades sociocognitivas, tais como a habilidade de atenção conjunta e de comunicação intencional, consideradas fundamentais para a aquisição da linguagem oral.

\section{Considerações finais}

Os resultados do presente estudo permitiram obter informações importantes sobre as percepções maternas acerca das habilidades sociocomunicativas dos bebês no primeiro ano de vida. Podem ser notadas variações nos relatos maternos em cada idade subsequentemente estudada. Durante as aplicações, percebeu-se que, para a maioria das mães estudadas, a comunicação estaria relacionada ao início da vocalização e, principalmente, da fala, o que pode influenciar a percepção e, em consequência, as interações. Por outro lado, a maioria das mães relatou o uso de gestos como o principal veículo comunicativo utilizado pelos bebês. Com o aumento de idade dos bebês, as mães relataram o uso dos gestos coordenados com vocalizações, principalmente aos doze meses.

A partir dos resultados obtidos no presente estudo, sugere-se que pesquisas posteriores incluam amostras com mães de níveis educacionais e socioeconômicos variados e com educadores e profissionais que trabalhem na interface desenvolvimentoeducação, o que possibilitaria obter dados relativos aos aspectos comunicativos da linguagem considerados pelos pesquisadores da área como uma dimensão crucial para o desenvolvimento. Esses estudos permitiriam repensar as práticas, as interações e o desenvolvimento infantil nos diversos contextos de inserção da criança, a partir de uma idade bem precoce.

Considera-se que conhecer as percepções acerca das habilidades sociocomunicativas de mães de bebês no primeiro ano de 
vida em diferentes momentos de seu desenvolvimento, seja através de um recorte longitudinal, seja transversal, possibilita acompanhar de que forma tais concepções vão se reconfigurando em virtude de novas habilidades de comunicação de natureza intencional adquiridas gradativamente pelos bebês ao longo do primeiro ano de vida. Ademais, os dados obtidos neste estudo devem ser discutidos mediante futuras pesquisas que analisem as percepções maternas acerca das habilidades sociocomunicativas de bebês no primeiro ano de vida, aspecto ainda pouco explorado em pesquisas da área, marcadamente no contexto brasileiro
Nessa direção, concorda-se com Dewart e Summers (1995) quando dizem que as informações promovidas pelo uso dessa entrevista são úteis no planejamento de intervenções com a criança, sua família, professores, profissionais e outros cuidadores. As propostas de intervenção geradas a partir das análises dos relatos dos adultos visam a fomentar a cooperação entre os profissionais e as pessoas importantes na vida da criança, no sentido de promover o desenvolvimento das habilidades sociocognitivas infantis e, dessa forma, contribuir para que as crianças, desde tenra idade, participem intensamente do mundo social.

\section{Fabíola de Sousa Braz Aquino:}

Professora do Departamento de Psicologia da Universidade Federal da Paraíba (UFPB), Doutora em Psicologia Social pela Universidade Federal da Paraíba, Paraíba - PB - Brasil.

Email: fabiolabrazaquino@gmail.com

\section{Nádia Maria Ribeiro Salomão:}

Professora do Programa de Pós-Graduação em Psicologia Social da Universidade Federal da Paraíba (UFPB) - Mestrado, e do Doutorado em Psicologia Social (UFPB), Doutora pela University of Manchester (UK), Pósdoutorado na University of North Carolina - Charlotte (USA).

Email:nmrs@uol.com.br

Endereço para envio de correspondência:

Rua Mário Batista Junior, 75; Ed. Quinta Avenida, apto 301. Bairro: Miramar, João Pessoa, PB, Brasil. CEP 58.043-130

Recebido 13/8/2009, 1a Reformulação 21/1/2011, Aprovado 31/3/2011. 


\section{Referências}

Adamson, L. B., \& Bakeman, R. (1985). Affect and attention: Infants observed with mothers and peers. Child Development, $56,582-593$

Bloom, L. (1993). The transition from infancy to language: Acquiring the power of expression. London: Cambridge University Press.

Bloom, L. (2000). Intentionality and theories of intentionality in development: Essay review of developing theories of intention. Human Development, 43, 178-185.

Braz Aquino, F. de S., \& Salomão, N. M. R. (2008). Intencionalidade comunicativa e atenção conjunta: uma análise em contextos interativos mãe-bebê. Tese de doutorado, Programa Integrado de Doutorado em Psicologia Social, Universidade Federal da Paraíba, João Pessoa, PB.

Bruner, J. S. (1980). Early social interaction and language acquisition. In H. R. Schaffer (Ed.), Studies in mother-infant interaction (pp. 271-289). New York: Academic Press.

Bruner, J. S. (1999). Intentionality of referring. In P. D. Zelazo, J. W. Astington, \& D. R. Olson (Eds.), Developing theories of intention: Social undertanding and self-control (pp. 329-339). Mahwah, NJ: Lawrence Erlbaum Associates.

Camaioni, L., Aureli, T., Bellagamba, F., \& Fogel, A. (2003). A longitudinal examination of the transition to symbolic communication in the second year of life. Infant and Child Development, 12, 1-26.

Carpenter, M., Nagell, K., \& Tomasello, M. (1998). Socia cognition, joint attention, and communicative competence from 9 to 15 months of age. Monographs of the society for research in child development, 63(4), 1-175.

Cleveland, A., Kobiella, A., \& Striano, T. (2006). Intention or expression? Four-month-old's reactions to a sudden still face. Infant Behavior \& Development, 29(3), 299-307.

Dewart, H., \& Summers, S. (1995). The pragmatics profile of everyday communication skills in children (Revised edition). Windsor: NFER-NELSON.

Dunn, J. (1999). Making sense of the social world: Mindreading, emotion, and relationships. In P. D. Zelazo, J. W. Astington, \& D. R. Olson (Eds.), Developing theories of intention: Social undertanding and self-control (pp. 229-242). Mahwah, NJ: Lawrence Erlbaum Associates.

Eilan, N. (2007). Joint attention, communication, and mind In N. Eilan, C. Hoerl, T. MacCormack, \& J. Roessler (Ed.) Joint attention: Communication and other minds: Issues in philosophy and psychology (pp. 1-33). New York: Oxford.

Feldman, R., \& Reznick, J. S. (1996). Maternal perception of infant intentionality at 4 and 8 months. Infant Behavior and Development 19, 483-496.

Feldman, C. F. (1999). Intentionality and interpretation. In P. D. Zelazo, J. W. Astington, \& D. R. Olson (Eds.), Developing theories of intention: Social undertanding and self-control (pp. 317-328). Mahwah, NJ: Lawrence Erlbaum Associates.

Feldman, R., Greenbaum, C. W., Mayes, L. C., \& Erlich, S. $H$. (1997). Change in mother-infant interactive behavior: Relations to change in mother, the infant, and the social context. Infant Behavior and Development 20(2), 151-163.

Feldman, R., \& Eidelman, A. I. (2004). Parent-infant synchrony and the social-emotional development of triplets.
Development Psychology, 40(6), 1133-1147.

Feldman, R. (2007). On the origins of background emotions: From affect synchrony to symbolic expression. Emotion, 7(3), 601-611.

Franco, F. (2007). Infant pointing: Harlequin, servant of two masters. In N. Eilan, C. Hoerl, T. MacCormack, \& J. Roessler (Ed.), Joint attention: Communication and other minds: Issues in philosophy and psychology (pp. 129-164). New York: Oxford

Gomes, R. C. O. (2008). Concepções de mães e professoras de educação infantil. In V. Vasconcellos, L. de Aquino, \& A. Dias (Orgs.), Psicologia e educação infantil (pp. 147-166). Araraquara, SP: Junqueira \& Marin Editores.

Gros-Louis, J., West, M. J., Goldstein, M. H., \& King, A. P. (2006). Mothers provide differential feedback to infants' prelinguistic sounds. International Journal of Behavioral Development, 30(6), 509-516.

Hains, S. M. J., \& Muir, D. W. (1996). Infant sensitivity to adult eye direction. Child Development, 67, 1940-1951.

Hobson, R. P. (1989). 'On sharing experiences'. Development and Psychopathology, 1, 97-203.

Halliday, M. A. K. (1979). One child's protolanguage. In M. Bullowa (Ed.), Before speech: The beginning of interpersonal communication (pp.171-190). London: Cambridge University Press.

Hsu, H., \& Fogel, A. (2001). Infant vocal development in a dynamic mother-infant communication system. Infancy, 2(1), 87-109.

Karousou, A. (2003). Análisis de las vocalizaciones tempranas: su patrón evolutivo y su función determinante en la emergencia de la palabra. Tese de Doutorado. Universidad Complutense de Madrid.

Kreppner, K. (2001). Sobre a maneira de produzir dados no estudo da interação social. Psicologia: Teoria e Pesquisa, $17(2), 97-107$

Lavelli, M., Pantoja, A. P. F., Hsu, H., Messinger, D., \& Fogel, A. (2004). Using microgenetic designs to study change processes. In D. M. Teti (Ed.), Handbook of research methods in delopmental science (pp. 4-65). New York: Blackwell Publishers.

Leavens, D. A., \& Hopkins, W. D. (1999). The whole-hand point: The structure and function of pointing from a comparative perspective. Journal of Comparative Psychology, 113(4), 417-425.

Messinger, D. S., \& Fogel, A. (1998). Give and take: The development of conventional infant gestures. Merril-Palmer Quarterly, 44, 4-566.

Mundy, P., Block, J., Delgado, C., Van Heck, A. V. Pomares, Y., \& Parlade, M. V. (2007). Individual differences and the development of joint attention in infancy. Child Development, 78, 53-69.

Papaeliou, C. F., \& Trevarthen, C. (2006). Prelinguistic pitch patterns expressing communication' and 'apprehension'. Journal of Child Language, 33, 163-178.

Parade, S. H., \& Leerkes, E. M. (2008). The reability and validity 
of the infant behavior questionnaire-revised. Infant Behavior and Development, 31, 637-646.

Prior, M., Bavin, E. L., Cini, E., Reilly, S., Bretherton, L., Wake, M. \& Eadie, P. (2008). Influences on communicative development at 24 months of age: Child temperament, behavior problems, and maternal factors. Infant Behavior \& Development, 31, $270-270$

Reddy, V. (2007). Before the "third element": Understanding attention to self. In N. Eilan, C. Hoerl, T. MacCormack, \& J. Roessler (Ed.), Joint attention: Communication and other minds: Issues in philosophy and psychology (pp. 85-109). New York: Oxford.

Reznick, J. S. (1999). Influences on maternal attribuition of infant intentionality. In P. D. Zelazo, J. W. Astington, \& D. R. Olson (Eds.), Developing theories of intention: Social understanding and self-control (pp. 243-267). Mahwah, NJ: Lawrence Erlbaum Associates.

Reznick, J. S., \& Schwartz, B. B. (2001). When is an assessment an intervention? Parent perception of infant intentionality and language. Journal of American Academy of Child and Adolescent Psychiatry, 40(1), 11-17.

Ribas Jr, R. C., Seidl de Moura, M. L., \& Bornstein, M. H. (2007). Cognições maternas acerca da maternidade e do desenvolvimento humano: uma contribuição ao estudo da psicologia parental. Revista Brasileira de Crescimento e Desenvolvimento Humano, 17(1), 104-113.

Rivero, M. (2003). Los inícios de la comunicación: La intencionalidad comunicativa y el significado como procesos graduales. Anuário de Psicologia, 34(3), 337-356.

Seidl de Moura, M. L., Ribas, R. C., Piccinini, C. A., Bastos, A. C. Magalhães, C. M. C., Vieira, M. L., Salomão, N. M. R., Silva, A. M. P. M., \& Silva, A. K. (2004). Conhecimento sobre desenvolvimento infantil em mães primíparas de diferentes centros urbanos do Brasil. Estudos de Psicologia, 9, 421-429.

Seidl-de-Moura, M. L., Lordelo, E., Vieira, M. L., Piccinini, C. A., Siqueira, J. A., Magalhães, C. M. C., Pontes, F. A. R., Salomão, N., M., \& Rimoli, A. (2008a). Brazilian mothers' socialization goals: Intracultural differences in seven Brazilian cities. International Journal of Behavioral Development, 32(6), 465-472.

Seidl-de-Moura, M. L., Ribas, A. F. P., Seabra, K C., Pessôa, L. F., Nogueira, S. E., Mendes, D. M. L. F., Rocha, S. B., \& Vicente, C. C. (2008b). Interações mãe-bebê de um e cinco meses: aspectos afetivos, complexidade e sistemas parentais predominantes. Psicologia: Reflexão e Crítica, 21(1), 66-73.

Striano, T., \& Rochat, P. (1999). Developmental link between dyadic and triadic social competence in infancy. British Journal of Developmental Psychology, 17, 551-562.

Striano, T., \& Rochat, P. (2000). Emergence of selective social referencing in infancy. Infancy, 1(2), 253-264.

Striano, T., \& Liszkowski, U. (2005). Sensitivity to facial expression in the still face context by 3-, 6-, and 9-monthold infants. Infant Behavior and Development, 28(1), 10-19.
Striano, T., \& Bertin, E. (2005). Social-cognitive skills between 5 and 10 months of age. British Journal of Development Psychology, 23, 1-11.

Striano, T., \& Vaish, A. (2006). Seven-to-9-month-old infants use facial expression to interpret others' actions. British Journal of Developmental Psychology, 24, 753-760.

Tronick, E. Z. (1989). Emotions and emotional communication in infants. American Psychologist, 44(2), 112-119.

Tomasello, M. (1995). Joint attention as social cognition. In C. Moore, \& P. J. Dunham (Eds.), Joint attention: Its origins and role in development (pp. 60-83). Hillsdale, NJ: Lawrence Erlbaum Associates .

Tomasello, M. (1998). Reference: Intending that others jointly attend. Pragmatics \& Cognition, 6(1/2), 229-243.

Tomasello, M. (2003). Origens culturais da aquisição do conhecimento humano. (C. Berliner, Trad.). São Paulo: Martins Fontes. (Coleção Tópicos).

Tomasello, M., Carpenter, M., \& Liszkowski, U. (2007). A new look at infant pointing. Child development, 78(3), 705-722.

Trevarthen, C. (2004). Learning about ourselves, from children: Why a growing human brain needs interesting companions. In Perception in action publications. (pp. 1-36). Scotland: University of Edinburgh.

Papaeliou, C. F. \& Trevarthen, C. (2006). Prelinguistic pitch patterns expressing 'communication' and 'apprehension'. Journal of Child Language, 33, 163-178.

Volterra, V., Caselli, M. C., Capirci, O., \& Pizzuto, E. (2004). Gesture and the emergence and development of language. In M. Tomasello, \& D. Slobin, (Eds.), Elizabeth Bates: A festschrift. Mahwah, NJ: Lawrence Erlbaum Associates.

Vygotsky, L. S. (1996). El primer año. In Obras Escogidas: Psicología infantil. (L. Kuper, Trad., Tomo IV, pp. 275-318). Madrid: Visor. (Trabalho original publicado em 1932).

Wetherby, A., \& Prizant, B. (1998). Communication and symbolic behavior scales development profiles. Research Edition. Chicago: Applied Symbolix.

Woodward, A. L. (2007). Infants' understanding of the actions involved in joint attention. In N. Eilan, C. Hoerl, T. MacCormack, \& J. Roessler (Ed.), Joint attention: Communication and other minds: Issues in philosophy and psychology (pp. 110-128). New York: Oxford.

Yale, M. E., Messinger, D. S., Delgado, C. F., \& Cobo-Lewis, A. B. (2003). The temporal coordination of early infant communication. Developmental Psychology, 39(5), 815-824. 